\title{
A Content Evaluation of Iranian Pre-university ELT Textbook
}

\author{
Ataollah Maleki \\ English Language Department, University of Medical Sciences, Zanjan, Iran \\ Fariba Mollaee \\ English Language Department, University of Zanjan, Iran \\ Robab Khosravi \\ English Language Department, University of Zanjan, Iran
}

\begin{abstract}
Textbooks and instruction materials are one of the most important components in any language classrooms all over the world. Considering the significant role of textbook in teaching/learning process, it is therefore very important to conduct EFL textbook evaluation so as to ensure ELT textbooks can effectively facilitate the attainment of the teaching objectives, and at the same time, be economically viable to teachers and students. The present study has attempted to evaluate the Iranian pre-university ELT textbook. To the end, four research questions were posed to determine whether the language used in the pre-university English textbook is authentic, whether the conversations, grammar rules, vocabulary words and expressions presented in this book are used in real-life situations, whether the activities and exercises included in the book are appropriate for communicative learning, and whether the texts, examples, and illustrations of this book are variable enough. Four EFL teachers and 335 pre-university students participated in this study. The evaluation was carried out through an ESL textbook evaluation checklist by Joshua Miekley (2005). The questions take the form of Likert scale. Rating scaled are numerically coded as 1 - totally lacking, 2 - poor, 3 - adequate, 4 good, 5 - excellent. Following the submission of the questionnaire, the obtained data were analyzed by SPSS which revealed unforeseen results that the participants were not mostly satisfied about this English textbook, because the calculated mean for all the questions were below 3. Therefore the four null-hypotheses were supported.
\end{abstract}

Index Terms - material, textbook, evaluation, authentic language, real-life situation

\section{INTRODUCTION}

A textbook can be referred to as a published book especially designed to help language learners to improve their linguistic and communicative abilities (Sheldon, 1987). The significant role of textbook in language classrooms has been supported by a number of other scholars. Hutchinson and Torres' statement that no teaching-learning situation is complete until it has its relevant textbook is worth considering in some depth $(1994$, p. 315). Other theorists hold similar view and assert that textbook continues to play an essential role in ELT classrooms all over the world (Dendrinos, 1992; Lee, 1997; Williams, 1983).

Sheldon (1988) stresses the importance of using textbooks as the visible heart of any ELT program which offer considerable advantages for both the student and the teacher. O'Neill (1982), for instance, implies that textbooks are generally sensitive to students' needs, even if they are not designed specifically for them. Haycroft's (1998) observation that textbooks are psychologically essential for students since their progress and achievement can be measured concretely is another advantage of using textbook.

The use of textbooks in classroom may provide other advantages for teachers as well. According to O'Neill (1982) and Sheldon (1988), textbooks can reduce potential occupational overload and allow teachers the opportunity to spend their time undertaking more worthwhile pursuits. In addition, Cunningsworth (1995) points out that textbooks are a source of ideas and activities, a syllabus where they reflect pre-determined learning objectives, and support for less experienced teachers who have yet to gain in confidence.

Conversely, some other theorists cast doubt on the previous point of view and declare that inexperienced teacher may over rely on a textbook which might have the opposite effect of saving students from a teacher's deficiencies (O'Neill, 1982; Williams, 1983; Kitao \& Kitao, 1997).

Considering the significant role of textbook in teaching/learning process it is therefore very crucial to select an appropriate textbook which closely reflect [the needs of the learners and] the aims, methods, and values of the teaching program" (Cunningsworth, 1995, p. 7).Since EFL syllabus primarily is designed around the selected textbook (Garinger, 2002; Harmer, 2002), so it can determine the success or failure of an ELT course (Green, 1926; Mukundan, 2007). 
However, due to the enormous number of textbooks on the market, it is difficult to make a right choice (Cunningsworth, 1995; Green, 1926) and they are often purchased without careful analysis (Green, 1926; McGrath, 2002). Having questioned the appropriateness of the existed textbooks in the market, Tomlinson argues that most current global, local ELT textbooks are developed for commercial purposes but are not based on principles of language acquisition and development recommended by scholars and educators (Tomlinson, 2003, 2008 \& 2010).

In order to be ensured that careful selection is made, textbook evaluation can be carried out. One of the advantages of textbook evaluation according to Sheldon's (1988) statement is that a thorough evaluation would enable the managerial and teaching staff of a specific institution or organization to discriminate between all of the available textbooks on the market. Moreover, it would help teachers make optimum use of a book's strong points and recognizing the shortcomings of certain exercises, tasks, and entire texts.

It is therefore very important to conduct EFL textbook evaluation so as to select a textbook based on its pedagogical value because wrong choice of textbooks would be likely negatively affect both teaching and learning. Financial resources would also be wasted (Mukundan, 2007; Sheldon, 1988). To evaluate one of the English textbooks used in Iranian schools, the present study was conducted. This study attempts to engage in an analysis of the pre-university English textbook taught in Iranian schools to designate the pedagogic values as well as the strengths and weaknesses.

This study addresses the following research questions:

1. Is the language used in the Iranian pre-university English textbook authentic?

2. Are the conversations, grammar rules, vocabulary words and expressions presented in this book used in real-life situations?

3. Are the activities and exercises included in the book appropriate for communicative learning?

4. Are the texts, examples, and illustrations of this book variable enough?

On the basis of the above-mentioned research questions, the following null-hypotheses were formulated:

$\mathrm{H}_{0}$ 1: The language used in the Iranian pre-university English textbook is not authentic.

$\mathrm{H}_{0}$ 2: The conversations, grammar rules, vocabulary words and expressions presented in this book are not used in real-life situations.

$\mathrm{H}_{0}$ 3: The activities and exercised included in the book are not appropriate for communicative learning.

$\mathrm{H}_{0}$ 4: The texts, examples, and illustrations of this book are not variable enough.

\section{REVIEW OF THE LITERATURE}

According to the Longman Dictionary of Contemporary English (2001), evaluation is "the act of considering something to decide how useful or valuable it is". Similarly, Mertens (2005, p. 47) defines evaluation as "the process of determining the merit, worth or value of something". Material evaluation is one of the most important components of language teaching/learning instruction which helps teachers to acquire useful, accurate, systematic, and contextual insights into the overall nature of textbook material (Cunningsworth, 1995; Ellis, 1997).

A number of studies have been carried out in this field a few of which are mentioned below. A survey conducted by Litz (2005) to evaluate a textbook (English Firsthand 2) revealed some significant results. According to Litz's (2005) findings, this book which is used by all of the high-beginner English classes in the university's EFL program is a new addition to the ELT materials available on the market. Based on this study, some merits of EF2are as follows:

- The entire textbook package contains useful supplementary materials.

- EF2 manages to integrate the four language skills.

- It is very attractive and organized in a clear and logical manner.

- The activities and tasks in EF2 are basically communicative.

Having stated several strengths of this textbook, Litz (2005) argues that EF2 has some shortcomings, too. For instance, the activities of this book are mostly repetitive and do not lead to realistic discourse.

In another similar study, Mahmood et al. (2009) conducted a textbook evaluation both in Pakistan and elsewhere. They believed that there were no explicit criteria for textbook evaluation. Thus, they designed this study in order to develop criteria for review, evaluation and approval of quality textbooks in Pakistan. Based on Garvin's (1988) framework for quality products, they were able to develop a textbook evaluation criterion.

Al-Yousef (2007) evaluated the New Third Grade Intermediate English Course book in Saudi Arabia. He employed both quantitative and qualitative research design. The participants of this study included 184 students, teachers and supervisors. Both the quantitative and the qualitative findings of the study revealed that the participants had positive feelings toward this book, because the obtained mean score was above 2.0 out of 4.0. The content and the visuals of the textbook got the highest mean, while gradation and recycling and supplementary material own the lowest mean.

Furthermore, textbook evaluation has been the subject of interest in Iran. Currently education system in Iran is going through some kind of curriculum reforms. Development and production of textbooks is a continual process which needs continual and rigorous research and development.

Safarnavadeh et al. (2009) conducted a research project. The results of this evaluation indicate that the main goal pursued in the textbook is language components based on the structuralist perspective. Writing skills with emphasis on grammatical precision received more attention compared to others, following traditional stylistic sophistication and mechanistic applications and models. They further add that the content and activities of these English textbooks are 
designed based on traditional and mechanical methods. Safarnavadeh's work convincingly demonstrates the need for revising the English textbooks. Having assumed that the main shortcomings belong to theoretical realm, they state that the theoretical foundations largely need to be revised.

Kiyani et al. (2011) have carried out a study in which they discuss the national curriculum of teaching foreign languages from three perspectives. They point up several strengths in this curriculum, including: decentralization and increase in the time of teaching foreign language from 486 to 597 hours in the first and second grades of high school. The national curriculum on the other hand, possesses some drawbacks. The contradictory and the lack of coordination among the expressed goals for teaching foreign languages, lack of participation of experts in authoring these textbooks, inattention to needs analysis, etc. are just few examples of the existed demerits.

Another similar study by Jahangard (2007) perused the English textbooks of first, second, third and pre-university grades. The results of this study indicated that the English Textbook of pre-university has optimum quality in helping the students to learn the learning strategies. However the textbooks of first, second, and third grades require reviews and reconsideration.

Another similar article was published by Ahmadi Darani in 2002. In his article Ahmadi Darani sets out to evaluate the high school textbooks for EFL education in Iran. Some of the findings of this study can be summarized as:

- The purpose of every textbook should be stated in the foreword section, but high school textbooks lack this part.

- Less attention has been given to students' interests and individual differences in these textbooks.

- The time for teaching and learning these textbooks is not adequate.

- There is no teacher's manual for these textbooks.

- Although authentic language has been used but the conversations of these books are artificial and do not represent real situations.

- The content does not serve as a window into learning about the target language culture.

- Reading comprehensions are not interesting and they are boring for the teenagers.

- The new vocabulary words learned in one lesson are not repeated in subsequent lessons.

- The physical make- up and the cover of the books are appropriate and satisfactorily.

Karimi (2004) evaluated a Preparatory English Course, Books 1\&2. Followings are some of his findings:

- The texts are attractive. The exercises and activities are useful.

- Cassette tapes and educational films are available; however, slideshow, film script, large photos and flash cards do not exist.

- The publisher has provided the teacher's manual in which the strategies of teaching reading comprehension, grammar and vocabularies have been presented.

- The target language culture has not been mentioned.

- Reading comprehensions are attractive.

- The offered pronunciations in this textbook are not satisfactory.

- Attention has been paid to learners' interests.

- There are few pictures and they are not colorful and attractive. Although the mode of print, type, cover of the book and quality of papers are satisfactory.

Ahmadpoor (2004) declares the inadequacy of high school English textbooks in his workas follows:

- The use of unattractive, boring, outdated and incoherent texts in the book.

- Incorrect, inappropriate and unattractive pictures of the book.

- The lack of cohesion and proper relevance among the lessons and the texts of subsequent books.

- The lack of coordination between the size of contents and the time dedicated for them.

- Unattractiveness of grammar points and the shortage of variable activities.

- Containing nonstandard questions.

- Lack of logical manner and order of difficulty in presenting grammar points.

- Lack of transparency in the general purpose of the book.

\section{Methodology}

\section{Participants}

This study relied on the active participation of both teachers and students. 335 students, including 179 females and 156 males, were selected purposively from the 45 schools in Zanjan city. In addition, four English teachers in the same schools also were chosen as the participants of this study to fill out the questionnaire.

\section{Procedures}

The procedures followed in this study included both preparation and administration of the instruments and the analysis of the collected data. A brief explanation of each is given below.

Preparation of the questionnaire for the participants: The original form of this questionnaire by Joshua Miekley, 2005 was in English which has been translated to Persian by the researcher. Then the Persian checklist has been back translated to English by someone else. Finally the original questionnaire and translated one were compared by the third 
person to see if the translation was accurate in terms of structure and content. Regarding the reliability of the questionnaire, the calculated Cronbach's alpha value was 0.923 which indicated high reliability, internal consistency and homogeneity. This 21-item questionnaire was adapted to address certain variables including: a) content, b) vocabulary \& grammar, c) exercises \& activities, and d) attractiveness of the text and physical make-up.

Administration of the questionnaire: Empirical data were then collected by using the Persian form of the questionnaire as the evaluation instrument to conduct a post-use evaluation on Pre-university English textbook. The questionnaire was submitted to the participants whom had been chosen purposively.

Analysis of the collected data: Following the submission of the questionnaire, the obtained data were analyzed by SPSS.

\section{RESUlts}

\section{Descriptive Statistics}

Table 1 shows the distribution of sample according to their gender. As can be seen, the total number of male participants is 158 (156 students and 2 teachers) and the number of female participants is 181 (179 students and 2 teachers).

\section{Inferential Statistics}

In this study the items of the questionnaire took the form of Likert scale numerically coded as 1 - totally lacking, 2 poor, 3 - adequate, 4 - good, 5 - excellent. For investigating research questions T-test was employed, the results of which can be seen in table 2 .

Regarding the first research question which was about the authenticity of the language used in the pre-university English textbook, the obtained mean was below 3 demonstrating that the content of the book is poor and the language is not authentic enough.

In order to find out the usefulness of the vocabulary words and grammar rules in real-life situation, the second question was introduced. The obtained mean was again below 3. It would seem that the participants are not satisfied enough about the vocabulary and grammar of the book.

To answer the third research question discussing the appropriateness of the exercises and activities for communicative learning, seven questions were asked whose calculated mean was 2.57 , which is poor again.

The last part of the questionnaire was dedicated to the attractiveness of the text and physical make up. The calculated mean for this question was 2.35 showing that the text and illustrations of the book are not variable enough.

Stated briefly, it can be argued that most of the participants are critical of the pre-university English textbook. It is worth recalling that the obtained means for all questions were below 3 which challenges the content of this textbook and convincingly demonstrates the need for revising the English textbook.

TABLE(1):

SAMPLE DISTRIBUTIONACCORDINGTO GENDER

\begin{tabular}{l|l|l|l|l}
\multicolumn{5}{c}{ SAMPLE DISTRIBUTIONACCORDINGTO GENDER } \\
\hline Male & Frequency & Percent & Valid Percent & Cumulative Percent \\
\hline Female & 158 & 46.61 & 46.61 & 46.61 \\
\hline Total & 181 & 53.39 & 53.39 & 100.0 \\
\hline
\end{tabular}

TABLE (2):

THE RESULT OF T-TEST

\begin{tabular}{l|l|l|l|l|l|l}
\hline & Mean & df & Sig. (2- tailed) & Mean Differences & $\begin{array}{l}\text { 95\% Confidence Interval } \\
\text { of the Difference }\end{array}$ \\
\cline { 3 - 7 } & & & & & LowerUpper \\
\hline First Research Question & 2.66 & 335 & .121 & .07619 & -.0201 & .1725 \\
\hline Second Research Question & 2.71 & 337 & .000 & .21775 & .1163 & .3192 \\
\hline Third Research Question & 2.57 & 337 & .116 & .07650 & -.0190 & .1720 \\
\hline Fourth Research Question & 2.35 & 337 & .009 & -.14497 & -.2535 & -.0364 \\
\hline
\end{tabular}

\section{CONCLUSION AND Discussions}

The results of this study confirm the findings of previous studies mentioned in the review of the literature under the title of Textbook Evaluation in Iran. In order to answer the first research question considering the authenticity of the language used in the pre-university English textbook, Kiyani et al (2011) state that the lack of participation of experts in authoring these textbooks is one of the existed demerits of national program. Darani (2002) also points out that the content of high school textbooks does not serve as a window into learning about the target language culture. Karimi (2004) proves this claim asserting that the target language culture has not been mentioned. These findings are in line with the result of the current study which showed that the language of the English textbook is not authentic.

The second question of this study deals with the usefulness of the vocabulary words and grammar rules in real-life situation. Regarding the grammatical rules, Safarnavadeh et al (2009) argue that in the writing activities based on the grammatical points, students are supposed to change the sentence according to the specific pattern, make a sentence 
using the given vocabularies; combine two sentences, etc. without having any freedom or creativity. This lack of freedom and creativity in using the vocabulary and grammar shows that students cannot use them in real life situation; in addition, Ahmadpoor (2004) notes that there is no logical manner and order of difficulty in presenting grammar points.

In response to the third question of the research about the appropriateness of the exercises and activities for communicative learning, Safarnavade et al (2009) maintain that the content and activities of these English textbooks are designed based on traditional and mechanical methods. Having evaluated different activities and exercises of the English textbooks including language function, speaking, listen \& repeat, reading, and writing based on the activities provided by Chastain (1988) and Rivers (1981, 1978), they further add that none of the eight activities set out by Chastain to improve listening skill, can be found in the English textbooks of high school. They also comment that speaking exercises are primarily in the form of imperative sentences. Similarly, Ahmadi Darani (2002) observes that the conversations of these books are artificial and do not represent real situations. Consequently, the result of the current study supports these claims and elucidates the inappropriateness of the activities and exercises included in the book for communicative learning.

The fourth question focusing on the attractiveness and physical make-up of the book, achieved similar findings to ones in the review of the literature. According to Karimi (2004), it seems that the number of the pictures is low yet they are not colorful and attractive. Ahmadpoor (2004) also declares the inadequacy of high school English textbooks due to the unattractive, boring, outdated and incoherent texts, and incorrect, inappropriate and unattractive pictures of the book. Unattractiveness of grammar points and the shortage of variable activities are the other demerits mentioned by Ahmadpoor.

In summary, the textbook is an important element of ELT program whose significant role in language classrooms has been supported by a number of scholars. Considering the significant role of textbook in teaching/learning process it is therefore very crucial to select an appropriate textbook; however, due to the enormous number of textbooks on the market, it is difficult to select an appropriate one. In order to be ensured that careful selection is made, textbook evaluation can be carried out so as to ensure ELT textbooks can effectively facilitate the attainment of our teaching objectives, and at the same time, be economically viable to teachers and students. The ELT textbooks used in Iranian schools are under the jurisdiction of the Ministry of Education. This study carried out to evaluate one of these English textbooks, i.e. English textbook of pre-university grade. The findings revealed that there are some existed demerits for this English textbook which need to be revised.

\section{REFERENCES}

[1] Al-Yousef, H. (2007). An Evaluation of the New Third Grade Intermediate English Coursebook in Saudi Arabia. Unpublished Master Thesis, College of Arts, Department of English, King Saud University, Riyadh, Saudi Arabia.

[2] AhmadiDarani,P.(2002). The Evaluation of High School Textbooks for EFL Education in Iran: The Evaluation via Checklist.FLT Journal, Vol. 64, 22- 32.

[3] Ahymadpoor.Z. (2004).Studying the Problems of EFL Teaching in High Schools. The Roshd ELT Journal, 18 (71), $15-21$.

[4] Chastain K. (1988). Developing second language skills. University of Virginia, Third edition.

[5] Cunningsworth, A. (1995). Choosing Your Coursebook. UK: Heinemann English Language Teaching.

[6] Dendrinos, B. (1992). The EFL Textbook and Ideology. Greece: N. C. Grivas publications.

[7] Ellis, R. (1997). The Empirical Evaluation of Language Teaching Materials. ELT Journal, Vol. 51(1), 36-42.

[8] Garinger, D. (2002). Textbook Selection for EFL Classroom. Eric Digest. Retrieved on January 11, 2010, from www.cal.org/resources/digest/digest-pdfs/0210 garinger.pdfs.

[9] Garvin, D.A. (1988). Managing Quality: The Strategic and Competitive Advantage. New York: Free Press.

[10] Green, A. (1926). The Measurement of modern language Books. The Modern language Journal, 10(5), 259-269.

[11] Harmer, J. (2002). The Practice of English Language Teaching. London: Longman.

[12] Hutchinson, T. \& Torres, E. (1994). The Textbook as Agent of Change. ELT Journal, 48(4), 315-328.

[13] Haycroft, J. (1998). An Introduction to English Language Teaching. London: Longman.

[14] Jahangard, A. (2007). Evaluation of EFL materials taught at Iranian public high schools. The Asian EFL Journal, 9(2), 130-150.

[15] Karimi,A. (2004). An Evaluation of A Preparatory English Course, Books 1\&2: An EAP Coursebook Evaluation.FLT Journal,Vol. 73, 24-28.

[16] Kitao, K. \& Kitao, S. (1997). Selecting and Developing Teaching/Learning Materials. Retrieved on July 13, 2004 from World Wild Web http://iteslj.org/

[17] Kiyani, G. Navidiniya, H. \&Momeniyan, M. (2011). Critical Review of National Program: Revisiting the Approach of National Curriculum towards Foreign Language Education. Jesarathaye Zabani Journal, 2(6), p. 185.

[18] Lee, W. (1997).'The Role of Materials in Classroom Language Use'.In V. Berry., B. Admson.\& W. Littlewood. (Eds), Applying Linguistics: Insights into Language Education(pp.69-82). Hong Kong: The University of Hong Kong.

[19] Litz, D. R. A. (2005). Textbook Evaluation and ELT Management: A South Korea Case Study. Asian EFL Journal, $48,1-53$. Retrieved on February 12, 2014 from http://www. asian.efl-journal.com/Litz - thesis.pdf.

[20] Longman Dictionary of Contemporary English. (2001). Third edition. Harlow: Pearson Education Limited.

[21] Mahmood, K. ZafarIqbal, M. \&Saeed, M. (2009). Textbook Evaluation through Quality Indicators: The Case of Pakistan. Bulletin of Education and Research December, 32(2), 1-27.

[22] Mares, C. (2003).'Writing a coursebook'. In B. Tomlinson (Ed), Developing Materials for Language Teaching (pp. 130-140). London: Continuum. 
[23] Mertens, D. M. (2005).Research and evaluation in education and psychology. $2^{\text {nd }}$ Edition. California: Sage Publications Inc.

[24] McGrath, I. (2002). Materials Evaluation and Design for Language Teaching. Edinburgh: Edinburgh University Press.

[25] Miekly, J. (2005). EFL evaluation Checklist. The Reading Matrix, 5(2), 1-9.

[26] Mukundan, J. (2007). 'Evaluation of English Language Textbooks: Some Important Issues for Consideration'. Journal of NELTA, Vol. 12 (1 \& 2), 4-80.

[27] O'Neill, R. (1982). 'Why Use Textbooks?'. ELT Journal, Vol. 36 (2), 104-111.

[28] Rivers, Wilga M. \&Temperlely, Mary S. (1978).A practical guide to the Teaching of English as a second or foreign language. Oxford University Press.

[29] Rivers, Wilga M. (1981).Teaching Foreign Language Skills. $2^{\text {nd }}$ ed. The University of Chicago Press.

[30] Safarnavadeh, Kh. Aliasgari, M. Mosapour,N. \&Ananisarab.(2009). Evaluation of high school English language textbook based on the criteria derived from communicative approach to teaching. Journal of Curriculum Studies (J.C.S.). Vol. 5(17), 86 114.

[31] Sheldon, L. E. (1987). ELT Textbook and Materials: Problems in Evaluation and Development. Oxford: Modern English Publication/The British Council.

[32] Sheldon, L. E. (1988). Evaluating English Language Teaching textbooks and materials. ELT Journal, 42 (4), 237-246.

[33] Tomlinson, B. (Ed.) (2003). Developing Materials for Language Teaching. London: Continuum.

[34] Tomlinson, B. (Ed.) (2008). English Language Learning Materials: A Critical Review. London: Continuum.

[35] Tomlinson, B. (2010). Principles of Effective Materials Development.In N, Harwood (ed.) (2010).English Language Teaching Materials: Theory and Practice. New York: Cambridge University press.

[36] Williams, D. (1983). Developing Criteria for Textbook Evaluation. ELT Journal. 37(3), 251-255.

Ataollah Maleki is Professor of Applied Linguistics at Zanjan University of Medical Sciences. He has published extensively with many international journals. He has also published a number of books related to language and language teaching.

Fariba Mollaee is an MA graduate of TEFL and teaches at language institutes in Zanjan, Iran.

Robab Khosravi obtained her PhD in English Literature from Keele University, United Kingdom. She is currently Assistant Professor and the Head of the English Language Department at University of Zanjan, Iran. Her main research interests are Modernism, the twentieth-century poetry (the work of T. S. Eliot in particular), critical theory, and aspects of postmodern thought and culture. 